\title{
Temperature Oscillations in Loop Heat Pipe Operation
}

\author{
Jentung Ku ${ }^{1}$, Laura Ottenstein ${ }^{1}$, Mark Kobel ${ }^{1}$, Paul Rogers ${ }^{2}$,Tarik Kaya ${ }^{3}$ \\ ${ }^{I}$ NASA Goddard Space Flight Center, Greenbelt, MD 20771, (301) 286-3130, jentung.ku@gsfc.nasa.gov \\ ${ }^{2}$ U.S. Army, TARDEC, Warren, Michigan, (810)574-5690, rogersp@icc.tacom.army.mil \\ International University, Strasburg, France, kaya@isu.isunet.edu
}

\begin{abstract}
Loop heat pipes (LHPs) are versatile two-phase heat transfer devices that have gained increasing acceptance for space and terrestrial applications. The operating temperature of an LHP is a function of its operating conditions. The LHP usually reaches a steady operating temperature for a given heat load and sink temperature. The operating temperature will change when the heat load and/or the sink temperature changes, but eventually reaches another steady state in most cases. Under certain conditions, however, the loop operating temperature never really reaches a true steady state, but instead becomes oscillatory. This paper discusses the temperature oscillation phenomenon using test data from a miniature LHP.
\end{abstract}

\section{INTRODUCTION}

Loop Heat Pipes (LHPs) are two-phase heat transfer devices which utilize the evaporation and condensation of the working fluid to transfer heat, and the surface tension forces developed in the fine porous wicks to circulate the working fluid. Figure 1 shows the schematic of a typical LHP, which consists of an evaporator, a compensation chamber, a condenser, and vapor and liquid transport lines. The entire loop is made of smooth wall tubing except the evaporator and the compensation chamber. The evaporator contains fine pore wicks which develop the necessary pumping forces to circulate the fluid around the loop. The compensation chamber is usually made as an integral part of the evaporator, and is connected to the evaporator by a secondary wick with coarser pores. The secondary wick draws liquid from the compensation chamber to the evaporator, thus ensuring the evaporator will not be deprived of liquid and become vapor locked. Such a feature makes it possible to start the LHP by applying power directly to the evaporator without pre-conditioning. It also makes LHP operation very robust because the evaporator can accommodate vapor inside the core.

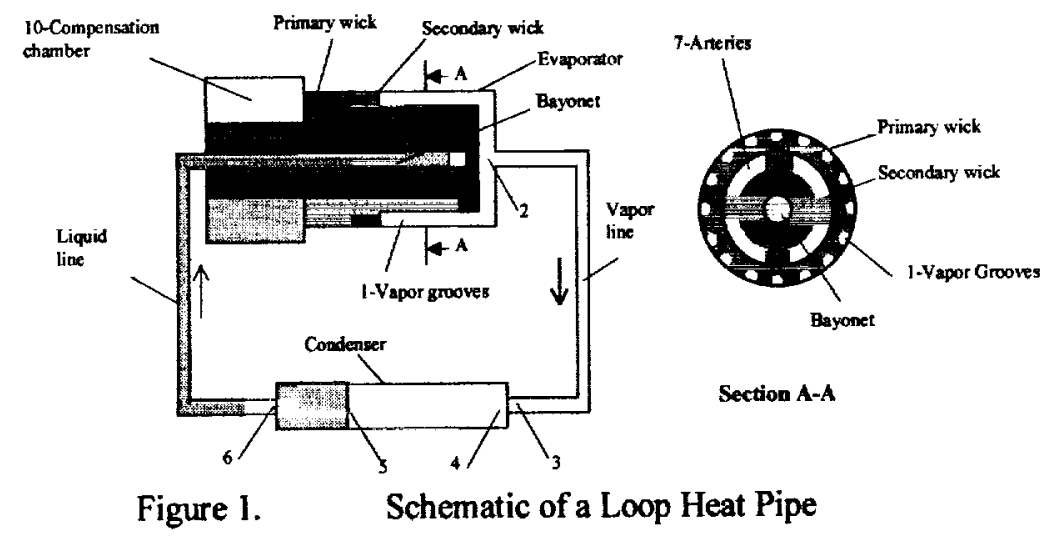

On the other hand, the integral construction of the evaporator and compensation chamber also yields some unique characteristics in the L.HP operation. The physical proximity and the secondary wick link between the 
evaporator and the compensation chamber means these two components are thermally and hydraulically coupled. In addition, the fact that the circulating flow passes right through the compensation chamber means the loop operating temperature is a function of its operating conditions. Extensive ground testing in the past few years revealed some peculiar behaviors such as the temperature overshoot during start-up and the temperature hysteresis. The present paper will discuss another interesting phenomenon that has been observed during LHP ground tests, namely the oscillation of loop temperatures.

Under certain operating conditions, the loop temperatures can oscillate indefinitely. The phenomenon of temperature oscillation will be described in detail using test data from a miniature LHP. The cause of the temperature oscillation will then be examined, and some explanations will be presented.

\section{MINIATURE LHP}

The test loop is a miniature LHP as shown schematically in Figure 2. The miniature LHP has an envelope dimension of $178 \mathrm{~mm} \times 127 \mathrm{~mm} \times 51 \mathrm{~mm}$ ( $7 \mathrm{in} . \times 5 \mathrm{in} . \times 2 \mathrm{in}$.) and a mass about 160 grams. The evaporator is made of aluminum and has an outer diameter of $13 \mathrm{~mm}$ and a length of $120 \mathrm{~mm}$. The compensation chamber is made of stainless steel with an outer diameter of $13 \mathrm{~mm}$ and a length of $30 \mathrm{~mm}$. The condenser, vapor line and liquid line are all made of the same size aluminum tubing $(2.8 \mathrm{~mm}$ L.D.) with lengths of $100 \mathrm{~mm}, 160 \mathrm{~mm}$, and $130 \mathrm{~mm}$, respectively. The working fluid is ammonia. The miniature LHP is contained in a box-like frame structure along with the heater and coolant blocks. It was mounted on a spin table and rotated about a central axis at various spin rates, including the stationary condition. The equivalent forces are $1.2 \mathrm{~g}$ 's at $30 \mathrm{rpm}$ and $4.8 \mathrm{~g}$ 's at $60 \mathrm{rpm}$. Tests were conducted by varying the evaporator power, the condenser sink temperature and the accelerating force.

Fifty-three type $\mathrm{T}$ thermocouples are used to monitor the temperatures of the loop. More detailed information on the test article and test set-up can be found in References 1 and 2.

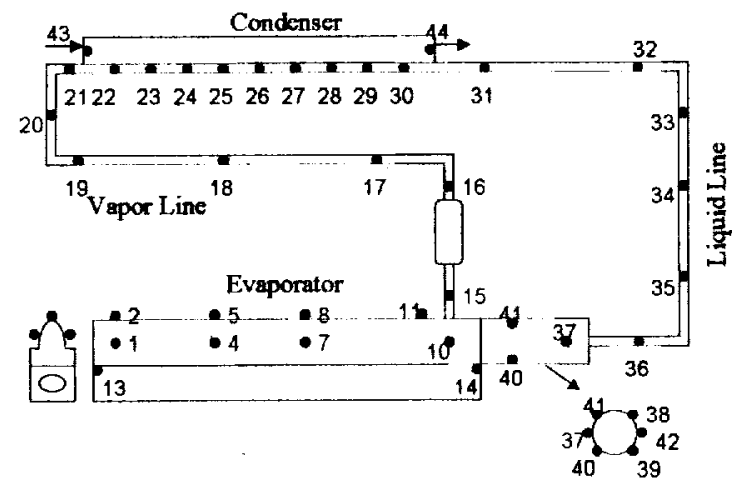

Figure 2. Schematic of Miniature LHP with Thermocouple Locations

\section{LHP OPERATING TEMPERATURE}

Since the saturation temperature of the compensation chamber determines the loop operating temperature, any factors that affect the compensation chamber temperature will directly impact the loop operating temperature. A detailed description of the LHP operating temperature as a function of operating conditions was given in Reference 3. The compensation chamber can exchange energy with the environment, the evaporator, and the liquid returning from the condenser. For a well-insulated compensation chamber in ambient tests, its heat exchange with the environment is very small and can usually be neglected.

The heat transfer between the compensation chamber and the evaporator depends on the composition of the fluid inside the evaporator core (the entire region inside the primary wick). If the evaporator core is completely filled with liquid, heat transfer is achieved mainly by conduction through the hermetic case and is usually very small. If the evaporator core contains vapor, however, the evaporator core essentially becomes part of the 
compensation chamber and heat transfer is greatly increased due to a much reduced heat transfer path. Heat can be conducted from the evaporator outer surface through the primary wick to the evaporator core, and then transmitted to the compensation chamber by evaporator and condensation along the vapor arteries. Heat transfer under this mode can be orders of magnitude higher than that by heat conduction through the hermetic case alone. The heat transmitted from the evaporator to the compensation chamber is commonly referred to as the heat leak.

The heat exchange between the compensation chamber and the returning liquid depends on the mass flow rate and the degree of subcooling of the returning liquid, which mixes with the fluid already in the compensation chamber. Furthermore, the liquid leaving the condenser, which is subcooled, can exchange heat with the ambient as it flows along the liquid line. Such a heat exchange is affected by the mass flow rate (a function of the heat load to the evaporator). Thus, the degree of subcooling of the liquid entering the compensation chamber depends on the condenser sink temperature, ambient temperature, and heat load.

For a well-insulated compensation chamber, the heat leak from the evaporator must be balanced by the subcooled liquid. Such an interaction yields the well-known "V" shape of operating temperature versus the evaporator power. At a very low heat load, the condenser is not fully utilized and the liquid leaves the condenser at a temperature close to the sink temperature. Because of the extremely low mass flow rate, however, the liquid is heated along the liquid line and its temperature will approach the ambient temperature as it enters the compensation chamber. As the heat load increases, the loop operating temperature decreases because a higher mass flow rate brings more subcooled liquid. This trend continues until the compensation chamber temperature reaches a minimum, which corresponds to a fully utilized condenser. Any increase of the evaporator power means the operating temperature must be raised in order to dissipate higher heat loads at the given sink temperature.

For a given operating condition, i.e. fixed heat load, condenser sink temperature, and ambient temperature, steady temperatures will be reached such that the energy balance is satisfied in the compensation chamber as well as other components of the LHP. As the operating condition changes, the loop operating temperature will change accordingly, but will eventually reach another steady state. Figure 3 show the steady operating temperatures in the miniature LHP test when the sink temperature was kept constant at $-40^{\circ} \mathrm{C}$ while the evaporator power varied between $25 \mathrm{~W}$ and $200 \mathrm{~W}$.

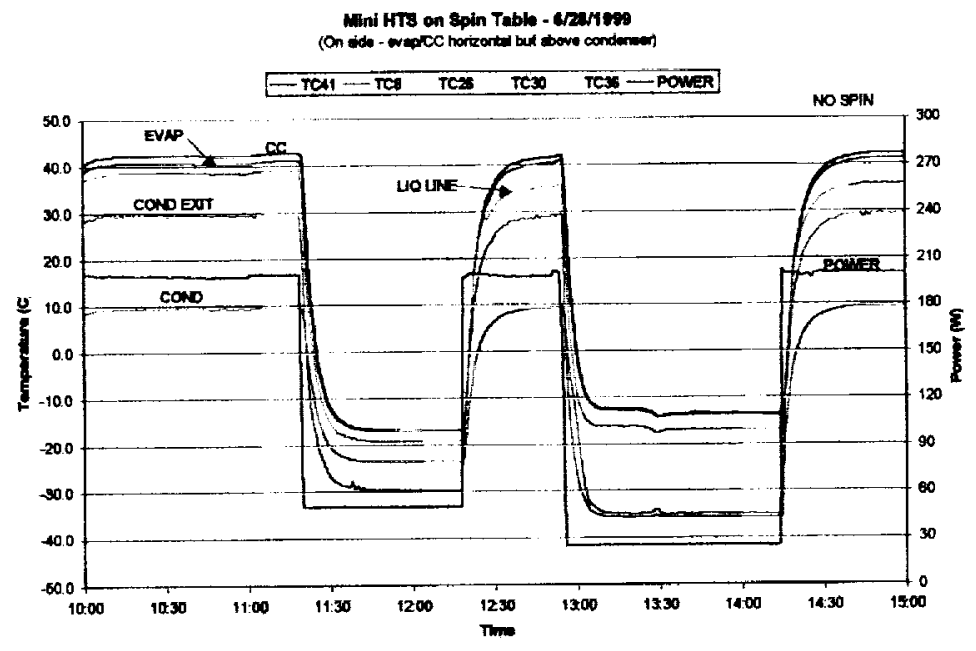

Figure 3. LHP Temperatures versus Heat Load

\section{TEMPERATURE OSCILLATION}

Under certain operating conditions, the LHP temperatures will not reach a steady state. Instead, the loop temperatures may oscillate indefinitely. Figure 4 shows the oscillatory nature of the miniature LHP temperatures when operating with $25 \mathrm{~W}$ heat load at $18^{\circ} \mathrm{C}$ sink temperature. The loop started with $23 \mathrm{~W}$ and appeared to approach 
a steady operating temperature. By increasing the evaporator power by $2 \mathrm{~W}$, the loop operating temperature dropped and then began to oscillate.

Temperature oscillations were observed throughout the test program. They were also seen in other LHPs. A careful analysis of the test data revealed that whenever the temperature oscillation occurred, the liquid/vapor interface (the vapor front) inside the condenser always moved back and forth around the condenser exit. In Figure 4, the condenser exit temperature (TC30) was much below the saturation temperature at $23 \mathrm{~W}$, and the loop operating temperature was steady. At $25 \mathrm{~W}, \mathrm{TC} 30$ jumped to the saturation temperature and began to oscillate. In fact, the temperature oscillation propagated through the liquid line all the way to the compensation chamber. The oscillation of the compensation chamber temperature further amplified temperature oscillations in the rest of the loop.

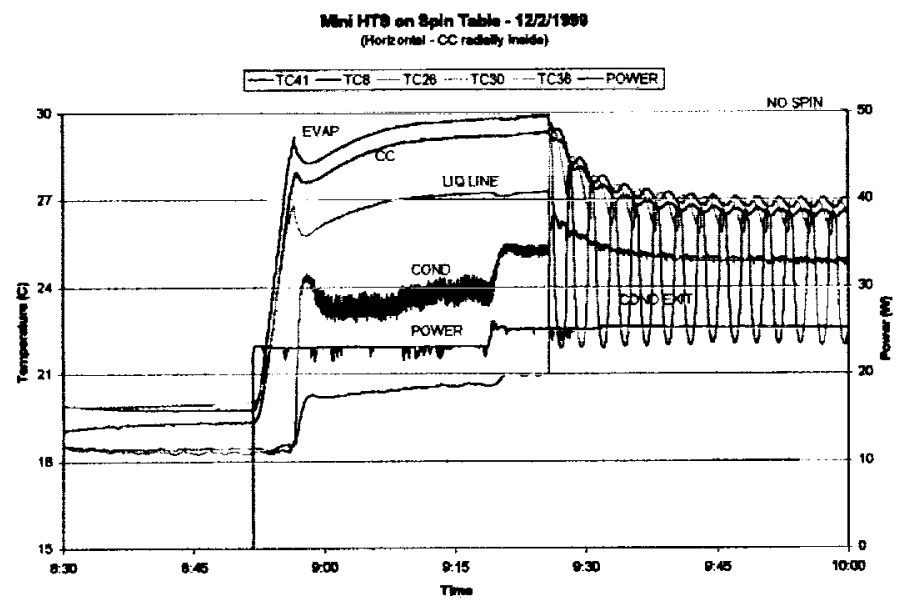

Figure 4. LHP Operating Temperature as a Function of Evaporator Power

The test shown in Figure 4 was continued by varying the sink temperature while keeping the evaporator power constant at $25 \mathrm{~W}$. The results are presented in Figures 5 . Initially, the sink temperature was set at $18^{\circ} \mathrm{C}$ and the loop temperatures oscillated. Temperature oscillations persisted as the sink temperature was lowered to $15.5^{\circ} \mathrm{C}$, and subsequently to $14^{\circ} \mathrm{C}$. Then as the sink temperature was lowered to $12.5^{\circ} \mathrm{C}$, temperature oscillations

disappeared. No temperature oscillations were seen as the sink temperature was raised to $13^{\circ} \mathrm{C}$ and $15.5^{\circ} \mathrm{C}$. Only when the sink temperature increased to $16.5^{\circ} \mathrm{C}$ did temperature oscillations re-appear. During the period when the loop operating temperature was steady, the condenser exit was at a subcooled temperature, indicating the vapor front stayed inside the condenser.

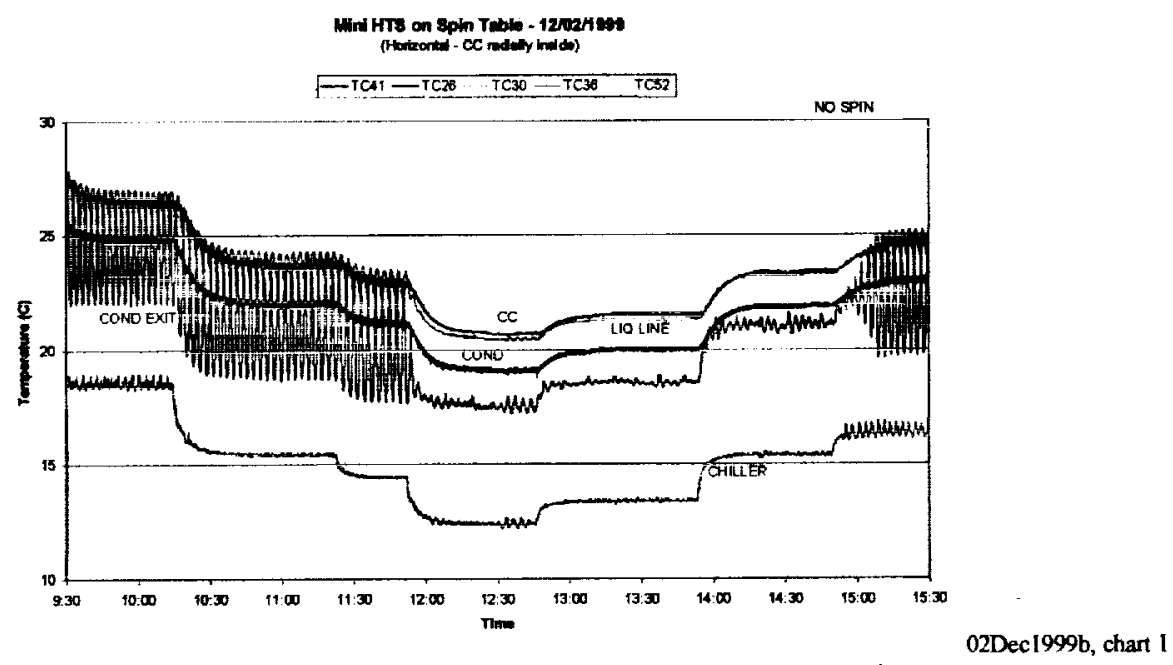

Figures 5. LHP Operating Temperature as a Function of Sink Temperature 
Since the compensation chamber temperature is affected by the heat leak from the evaporator and the returning subcooled liquid, either the heat leak is oscillating, or the temperature of the returning subcooled liquid is oscillating. Most likely, it is the combination of the two that makes the compensation chamber temperature to oscillate. Since the compensation chamber temperature controls the loop operating temperature, an oscillating compensation chamber temperature further makes the heat leak and the returning liquid temperature to oscillate. In other words, all loop components are thermally and hydrodynamically interrelated.

Specifically, in Figures 4 and 5, when the oscillating compensation chamber temperature reached its lowest value, the condenser was not able to dissipate the applied heat load. Consequently, the vapor front extended outside the condenser into the liquid line. A warmer fluid leaving the condenser raised the compensation chamber temperature. It could also make the vapor inside the evaporator core to expand, which increased the heat leak and further raised the compensation chamber temperature. As the compensation chamber increased, the vapor front began to recede from the liquid line back into the condenser because a smaller condensing area was needed for heat dissipation. At the peak of the compensation chamber temperature, the liquid leaving the condenser was at its lowest temperature. The colder returning liquid would lower the compensation chamber temperature. It could also reduce the heat leak by collapsing some vapor bubbles inside the evaporator core, further reducing the heat leak. Such cycles can continue indefinitely.

The vapor front locating near the condenser exit is a necessary condition for temperature oscillations. Once the vapor front recedes inside the condenser, temperature oscillations stop. Figure 6 shows the temperatures when the miniature LHP was subjected to a centrifugal force. In this test, the compensation chamber and the liquid line shown in Figure 2 were placed at the outer edge of the test fixture and the accelerating force was acting along the axis of the evaporator and the compensation chamber. At a constant heat load of $100 \mathrm{~W}$ and a constant sink temperature of $0^{\circ} \mathrm{C}$, the spin rates changed between $0 \mathrm{rpm}$ and $60 \mathrm{rpm}$. Notice how the accelerating force affected the temperature oscillation. Also notice the temperature hysteresis before and after the accelerating force was applied. It is postulated that the accelerating force changed two-phase fluid distributions in the evaporator core, the compensation chamber, and the condenser; thus changing the heat leak and the liquid subcooling leaving the condenser. At $0 \mathrm{rpm}$ and $30 \mathrm{rpm}$, the vapor front reached TC 30 and loop temperatures oscillated. At $60 \mathrm{rpm}$, the vapor front receded inside the condenser and loop temperatures were steady.

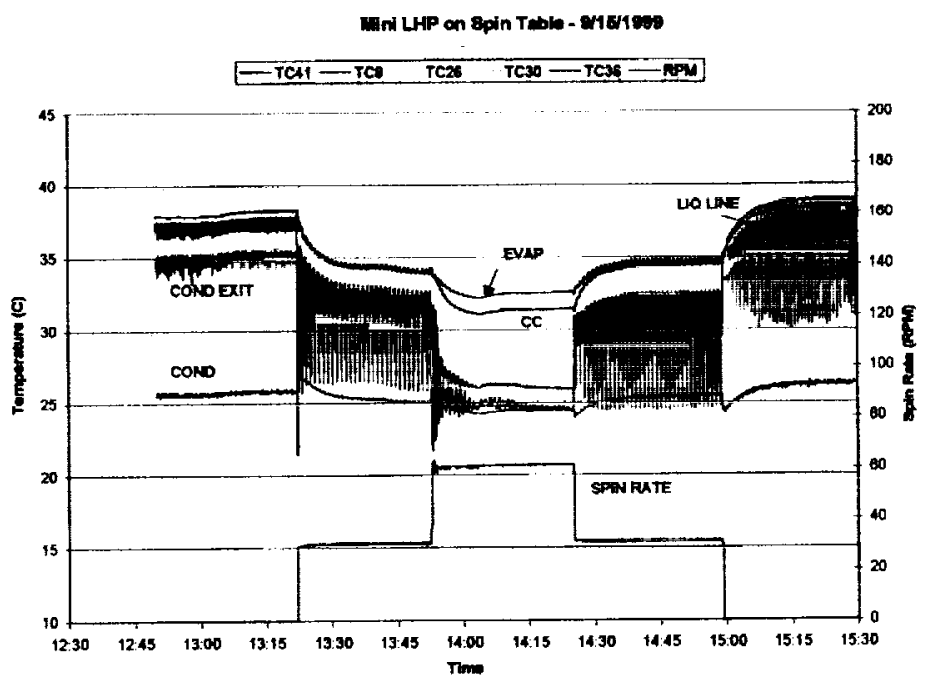

Figure 6. Loop Operating Temperature as a Function of Spin Rate in $100 \mathrm{~W} / 0^{\circ} \mathrm{C}$ Test

Figure 7 shows a continuation of the test from Figure 6, where the LHP was subjected to periodic accelerating forces. The loop temperatures oscillated at $0 \mathrm{rpm}$. Note the different temperature patterns when different accelerating forces were applied and during the intermittence. When the accelerating force was removed, the temperature oscillation almost disappeared. The effect of accelerating forces on the loop operating temperature is clearly illustrated. 


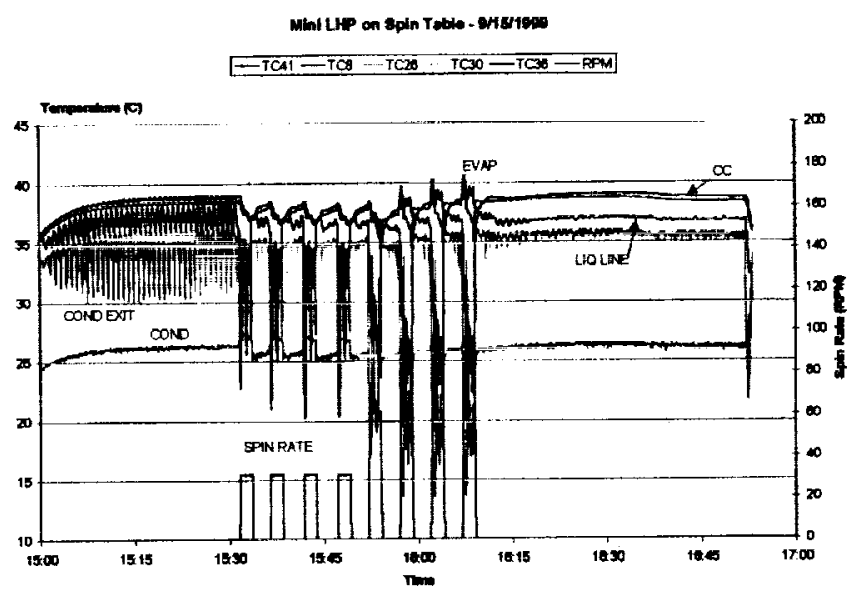

Fiqure 7. Effect of Accelerating Force on Loop Operating Temperature in $100 \mathrm{~W} /{ }^{\circ} \mathrm{C}$ Test

Figure 8 presents temperature profiles in the $25 \mathrm{~W} / 0^{\circ} \mathrm{C}$ test when the loop subjected to various accelerating forces. During the entire period, TC 30 (condenser exit) and TC 26 (condenser mid-point) was at subcooled temperatures, indicating that the vapor front never reached the condenser exit. Thus, no temperature oscillations were seen during the course of the test.

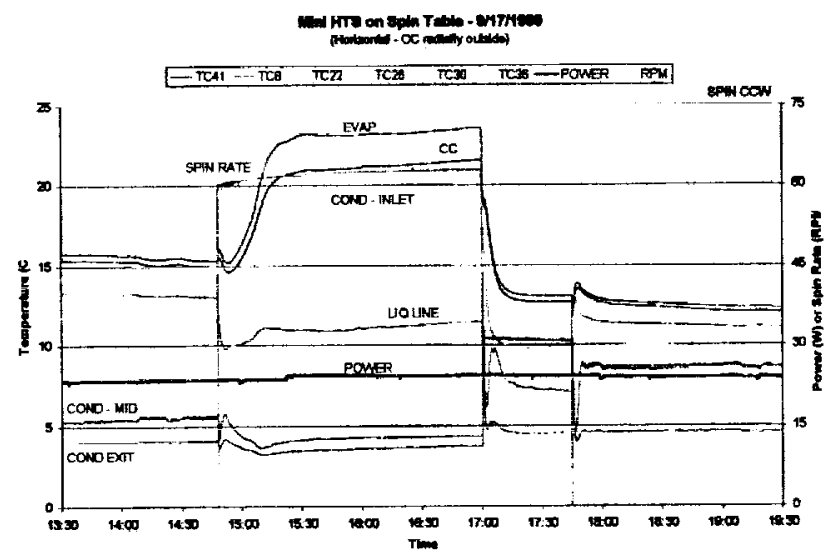

17Sep19991no, chart 1

Figure 8. Loop Operating Temperature as a Function of Spin Rate in $25 \mathrm{~W} / 0^{\circ} \mathrm{C}$ Test

Figure 9 shows the loop temperatures at a constant sink temperature of $-40^{\circ} \mathrm{C}$ with the evaporator power varying between $10 \mathrm{~W}$ and $200 \mathrm{~W}$. No temperature oscillations were seen at $10 \mathrm{~W}$ and $25 \mathrm{~W}$. The vapor front remained inside the condenser at these low powers. Large temperature oscillations were observed at $50 \mathrm{~W}$ and $100 \mathrm{~W}$. During this period, the front moved back and forth around the condenser exit. As the power increased to $150 \mathrm{~W}$ and $200 \mathrm{~W}$, however, temperature oscillations stopped. At these power levels, the loop adjusted its operating temperatures so that the vapor front receded into and remained inside the condenser. If mixing of liquids inside the compensation chamber and the returning flow alone causes the temperature oscillation, the oscillation should persist for any powers higher than the threshold value. Test results shown in Figure 9 indicate otherwise. The vapor fraction inside the evaporator must also change periodically during the temperature oscillation.

\section{CONDLUDING REMARKS}

The LHP operating temperature is governed by the compensation chamber temperature, which in turn is determined by the heat leak and the subcooling of the returning liquid. When the operating condition changes, the loop operating temperature changes accordingly. In most cases, the loop reaches a steady operating temperature. 


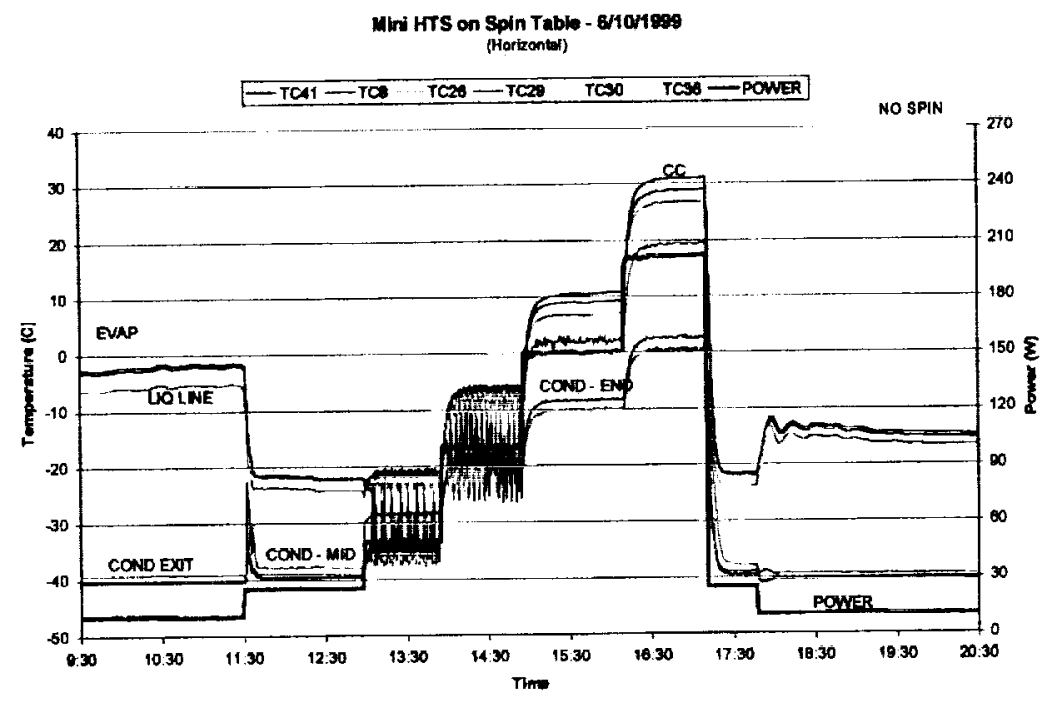

10Jun1999Ino, chart 1

Figure 9. Loop Operating Temperatures at $-40^{\circ} \mathrm{C}$ Sink Temperature

Under certain conditions, however, the loop operating temperature oscillates, and only a quasi-steady temperature can be reached.

It is postulated that the vapor void fraction inside the evaporator core is a key factor in determining the heat leak. Thus, when the void fraction changes, the loop operating temperature will also change. Furthermore, the loop can operate at different temperatures for the same heat load and sink temperature, depending on the void fraction. This is the essence of temperature hysteresis, which has been observed in many LHPs [2-6]. In an LHP, the fluid inventory and the volume of each component are fixed. The amount of fluid in each component will change as the operating condition changes. Hysteresis simply indicates that an LHP can operate at different states, all yielding stable operation, and still satisfies thermal and hydraulic requirements.

The temperature oscillation is caused by the thermal and hydrodynamic interactions between the evaporator, the compensation chamber and the condenser. The temperature oscillation is characterized by the vapor front moving inside and outside the condenser periodically. It is postulated that the rise and fall of the temperature of the liquid returning causes the compensation chamber temperature and the void fraction inside the evaporator core to increase and decrease. This postulate can not be directly verified since no flow visualization was made. However, this paper has presented many test results which seem to support such a theory. First, the temperature oscillation only occurs when the vapor front is moving back and forth around the condenser exit. Second, the temperature of the compensation chamber and that of the liquid leaving the condenser are always 180 degrees out of phase. Third, decreasing the sink temperature can cause the temperature oscillation to disappear, presumably due to the decrease of the void fraction resulting from vapor bubble collapse. Further, the temperature oscillation does not re-appear until the sink temperature is raised several degrees higher than the original threshold temperature. Fourth, accelerating forces definitely cause flow distributions to change among LHP components. The accelerating force can cause the temperature to oscillate from an initial steady condition. It can also cause the temperature oscillation to disappear.

In Figure 9, once the temperature oscillation occurred at $50 \mathrm{~W}$, one would expect the oscillation to continue at higher powers as it did at $100 \mathrm{~W}$. However, the oscillation disappeared at $150 \mathrm{~W}$ and $200 \mathrm{~W}$. The fact that the temperature oscillation occurs only under certain conditions is just another example of the complex phenomena of the LHP operation. A theoretical analysis or computer modeling will help gain a better understanding of the physical processes involved. The key is to accurately predict the void fraction inside the evaporator under various operating conditions. 


\section{REFERENCES}

1. Ku, J., Ottenstein, L., Kaya, T., Rogers, P., and Craig, H., "Testing of a Loop Heat Pipe Subjected to Variable Accelerating Forces, Part 1: Start-up," SAE paper No. 2000-01-2488, $30^{\text {th }}$ International Conference on Environmental Systems, July 10-13, 2000, Toulouse, France.

2. Ku, J., Ottenstein, L., Kaya, T., Rogers, P., and Craig, H., "Testing of a Loop Heat Pipe Subjected to Variable Accelerating Forces, Part 2: Temperatue Stability," SAE paper No. 2000-01-2489, $30^{\text {th }}$ International Conference on Environmental Systems, July 10-13, 2000, Toulouse, France.

3. Ku, J, "Operating Characteristics of Loop Heat Pipes," SAE Paper No. 1999-01-2007, $29^{\text {th }}$ International Conference on Environmental Systems, July 12-15, 1999, Denver Colorado.

4. Wolf, D., and Bienert, W, "Investigation of Temperature Control Characteristics of Loop Heat Pipe," SAE Paper No. 941576, $24^{\text {th }}$ International Conference on Environmental Systems, July 20-23, 1994, Friedrichshafen, Germany.

5. Cheung, M., Hoang, T., Ku, J., and Kaya, T, "Thermal Performance and Operational Characteristics of Loop Heat Pipe (NRL LHP)," SAE Paper No. 981813, $28^{\text {th }}$ International Conference on Environmental Systems, July13-16, Danvers, Massachusetts.

6. Kaya, T. and Ku, J., "Investigation of the Temperature Hysteresis Phenomenon of a Loop Heat Pipe," 1999 National Heat Transfer Conference, August 15-17, Albuquerque, New Mexico. 